\section{USING MACHINE LEARNING TO INTEGRATE ON-FARM SENSORS AND AGRO-METEOROLOGY NETWORKS INTO SITE-SPECIFIC DECISION SUPPORT}

\author{
J. Kelley, D. McCauley, G. A. Alexander, W. F. Gray IV, R. Siegfried, H. J. Oldroyd
}

Beyond 2020,

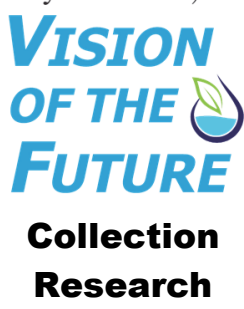

\title{
HighLIGHTS
}

- Machine learning can incorporate a variety of data from low-cost sensors and estimate actual ET by comparison with short-term, higher-cost measurements.

- On-farm weather monitoring can be leveraged to estimate site-specific crop-water requirements.

- Expanding spatial coverage of weather and actual ET through on-farm monitoring will facilitate localization and leverage publicly available weather data to guide irrigation decisions and improve irrigation water management.

\begin{abstract}
One of the basic challenges to adopting science-based irrigation scheduling is providing reliable, site-specific estimates of actual crop water demand. While agro-meteorology networks cover most agricultural production areas in the U.S., widely spaced stations represent regionally specific, rather than site-specific, conditions. A variety of low to moderate cost commercial weather stations are available but do not provide directly useful information, such as actual evapotranspiration $\left(E T_{a}\right)$, or the ability to incorporate additional sensors. We demonstrate that machine learning methods can provide real-time, site-specific information about ET a and crop water demand using on-farm sensors and public weather information. Two years of field experiments were conducted at four irrigated field sites with crops including snap beans, alfalfa, and pasture. On-farm data were compared to publicly available data originating at nearby agro-meteorology network stations. The machine learning procedure can robustly estimate $E T_{a}$ using data from a few basic sensors, but the resulting estimate is sensitive to the range of conditions that are used as training data. The results demonstrate that machine learning can be used with affordable sensors and publicly available data to improve local estimates of crop water demand when high-quality measurements can be co-located for short periods of time. Supplementary sensors can also be integrated into a tailored monitoring plan to estimate crop stress and other operational considerations.
\end{abstract}

Keywords. Agro-meteorology, Irrigation requirement, Machine learning, Site-specific Irrigation.

I nnovative irrigation technology offers many benefits, including improved crop yields, reduced losses from nonuniform application, reduced disease incidence, and conservation of water resources. However, adoption of innovative irrigation technology is slowed by a lack of information and decision support to ensure that new methods are reliable and cost-effective (Molden et al., 2010; Perry, 2007). The role of researchers and water resource professionals in promoting science-based irrigation methods should include demonstrations of new methods that are feasible to implement

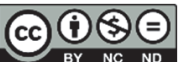

The authors have paid for open access for this article. This work is licensed under a Creative Commons AttributionNonCommercial-NoDerivatives 4.0 International License https://creative commons.org/licenses/by-nc-nd/4.0/

Submitted for review in January 2020 as manuscript number NRES 13917; approved for publication as a Research Article and as part of the National Irrigation Symposium 2020 Collection by the Natural Resources \& Environmental Systems Community of ASABE in May 2020.

The authors are Jason Kelley, Assistant Professor, and Dalyn McCauley, Student, Department of Soil and Water Systems, University of Idaho, Moscow, Idaho; G. Aaron Alexander, Student, Wilton F. Gray IV, Student, Rylie Siegfried, Student, and Holly J. Oldroyd, Assistant Professor, Department of Civil and Environmental Engineering, University of California, Davis, California. Corresponding author: Jason Kelley, MS 2060, 875 Perimeter Drive, University of Idaho, Moscow, ID 83844; phone: 208-885-1015; e-mail: jasonrk@uidaho.edu. and reliable in real-world conditions. A critical area of decision support is the provisioning of real-time, site-specific estimates of crop water requirements and crop evapotranspiration (ET). Real-time estimates of ET can support daily irrigation planning, address potential risks of under-application and yield reduction, identify crop water requirement for new varieties, and evaluate new strategies for addressing climate change and water scarcity. While state and federal agro-meteorology networks cover most agricultural production areas in the U.S., the widely spaced stations of most networks can only represent regionally specific, rather than site-specific, conditions (Evans and King, 2012). Because growers need site-specific weather measurements, a variety of low to moderate cost commercial weather stations are available. Although some of these commercial systems may be used to estimate reference ET, this information is not as directly useful to irrigators as would be estimates of crop water requirement $\left(\mathrm{ET}_{c}\right)$ or actual evapotranspiration $\left(\mathrm{ET}_{a}\right)$. In addition, most commercial weather stations and ET models cannot readily incorporate additional sensors that may be used by irrigators, such as soil water sensors or irrigation flow controls.

Other resources available to irrigators are irrigation support tools and public agro-meteorology networks operated 
by federal and state agencies (Haigh et al., 2018). AgriMet and the California Irrigation Management Information System (CIMIS) are two agricultural weather networks developed specifically to provide decision support to farmers with the goal of conserving water resources. The California Department of Water Resources funds and maintains 145 CIMIS weather stations across the entirety of California. The U.S. Bureau of Reclamation operates over 70 AgriMet stations across Oregon, Washington, and Idaho and some parts of Montana, Wyoming, and Nevada. In the northwestern states, another valuable resource is Washington State University's AgWeatherNet and Irrigation Scheduler software (Peters et al., 2014). These networks maintain automatic weather stations that report parameters including air temperature, relative humidity, wind speed and direction, precipitation, and solar radiation over a well-watered grass reference surface, and they also provide estimates of crop water demand via the Penman-Monteith (P-M) equation for reference ET. Depending on the individual sensor and data type, AgriMet generally reports weather data every $15 \mathrm{~min}$, and CIMIS reports hourly. Data are transmitted every hour from individual stations to a central server, where they undergo automatic and manual quality control procedures, and the data are made available through an automated web interface. The AgriMet quality assurance procedures include checks on data transmission metrics, upper and lower measurement limits, rate of change, and a manual graphical review. Additionally, lab calibration is performed on all sensors prior to deployment, and field calibrations are performed annually to ensure that the data are reliable and accurate (Palmer and Hamel, 2009).

Near real-time calculations of P-M reference ET and crop water demand are available on web interfaces for irrigators in the region. Reference ET is a measure of the weather-related crop water use over a well-watered reference surface. To estimate actual crop water demand, the reference ET is used with a one-term or two-term resistance model that accounts for crop development and soil evaporation in two separate terms (Allen et al., 2005) but cannot account for sitespecific effects such as non-uniform irrigation, soil characteristics, or crop varietal differences. The most common way for farmers to derive actual crop water demand is by adjusting reference ET with a calibrated crop coefficient (Daccache et al., 2015; Knox et al., 2012). The AgriMet, AgWeatherNet, and CIMIS networks provide tables of crop coefficients over the growing season so that farmers can select the most appropriate coefficients for their operations. Crop coefficients are typically developed from annual or longterm averages of water consumption by a specific variety of a specific crop and are most often based on studies using weighing lysimeters (Marek et al., 2006). Specific circumstances, such as the development of new crop varieties, early or late planting, or interannual differences in plant development, are not represented by simple crop coefficients and make it difficult for farmers to choose the correct coefficients. Many irrigation scheduling software packages can incorporate specific information to account for crop stress or practices such as cutting alfalfa (Peters et al., 2014), but this information requires an additional level of accounting and discretion on the part of the irrigator.
Estimates of crop ET are only as good as the calibrated crop coefficient. Applying the wrong coefficient can lead to inefficient or insufficient application, and this risk may outweigh the potential benefit of incorporating ET into irrigation decisions (Davis and Dukes, 2010). There are other methods that measure crop ET directly, including the eddycovariance (EC) method and weighing lysimeters, but these methods are costly, time-consuming, and the resulting estimates of crop response do not precisely transfer to all growing conditions or to new crop varieties (Allen et al., 2011). When growers use scientific irrigation planning to conserve water and maximize efficiency, there is a greater risk of drought stress and yield reduction, poor germination or development, reduction of crop quality, and incidence of disease (Perry et al., 2009). For example, scheduling irrigation without a site-specific measurement of actual ET can lead to misapplication, resulting in yield reductions, crop loss, and reduced water use efficiency (Evans et al., 2013). At present, irrigators and consultants base their decisions on a variety of regional weather forecasts and daily reference ET estimates from both public and private sources (Haigh et al., 2018). While there is a moderate degree of confidence in publicly available data, better utilization and adoption of scientific methods will require leveraging these data to provide realtime and site-specific estimates of crop ET without requiring excessive effort on the part of end-users.

Machine learning has seen increasing use in hydrology and climate science in recent years for predicting and modeling hydrologic processes (Govindaraju, 2000). Artificial neural networks (ANNs) are one form of machine learning, with algorithms that "learn" from data and approximate solutions for non-linear, multi-input functions. Due to their flexibility and robustness, ANNs have seen increasing application in modeling reference ET (Kumar et al., 2011), atmospheric fluxes (Alemohammad et al., 2017), plant water stress (King and Shellie, 2016; Meyers et al., 2019), and irrigation optimization (Irmak and Kamble, 2009). Because neural networks use optimization algorithms and do not depend on physical models, ANNs can be useful in circumstances where data quality is variable, and to explore non-linear behavior. In one approach to machine learning, supervised ANNs learn through a process of error minimization, in some ways resembling multi-linear regression, but using non-linear transfer functions to approximate the non-linear behavior observed in real data (Paliwal and Kumar, 2009).

Previously, a neural network machine learning procedure was demonstrated that was able to estimate daily $\mathrm{ET}_{a}$ robustly in actual field conditions (Kelley and Pardyjak, 2019). This approach used data from a few basic sensors and EC flux measurements as a control estimate of reference ET. The EC data were used to train a neural network for a relatively short time, and then the EC measurements were used to evaluate the robustness of the neural network in estimating ET over an entire field season. The resulting estimates were extremely sensitive to the variety of field conditions during collection of the training data. In practice, guiding irrigation decisions and estimating consumptive water use with machine learning has yet to be satisfactorily demonstrated. For practical purposes, these methods must work with data that can be monitored affordably in real-world 
conditions, and should only require direct evaporation measurements for the shortest possible training period. We propose that this approach can integrate research methods into tailored on-farm monitoring to estimate site-specific crop water requirements, optimize real-time irrigation scheduling, and improve water management.

\section{MATERIALS AND METHODS}

In order to demonstrate that machine learning methods can provide real-time, site-specific information about $\mathrm{ET}_{a}$ and crop water demand, field experiments were conducted in two different years in four irrigated fields growing snap beans, alfalfa, and pasture, all in proximity to regional agrometeorology or basic weather stations. These data were analyzed with simple (one and two layer) neural networks that were trained to estimate actual ET from on-farm data and local network weather records. The supervised machine learning algorithm used EC flux measurements to estimate site-specific ET.

This analysis used data collected during the 2017 and 2019 growing seasons in agricultural fields in Oregon and California. Each of the four experiments used the EC method to measure the actual rate of evapotranspiration $\left(\mathrm{ET}_{a}\right)$, which is treated here as the control estimate of $\mathrm{ET}_{a}$ and used in a supervised machine learning algorithm. Each site was equipped with supplemental sensors that are typically used in agro-meteorology networks and on-farm weather stations. In all cases, EC sensors were installed at a nominal height of $2 \mathrm{~m}$ above ground level. Additionally, some experiment sites were located directly adjacent to permanent agro-meteorology network sites, and the other experiments used the closest available ground-based weather data. Data were collected using dataloggers, stored in ASCII/binary files, or downloaded from public agro-meteorology networks. In California, hourly weather and reference ET records from the colocated CIMIS stations were downloaded from the CIMIS website (https://cimis.water.ca.gov). At the Oregon site, data were obtained from the five closest AgriMet (https://www.usbr.gov/pn/agrimet/) and AgWeatherNet (http://weather.wsu.edu/) stations. Data were then re-formatted for analysis in Matlab (MathWorks, 2018) using customized import scripts. The EC flux calculations, corrections, and quality control were performed with scripts prepared by one of the authors (Oregon site). For the California sites, $\mathrm{ET}_{a}$ was also calculated using EddyPro software (LI-COR, 2019). Machine learning algorithms were implemented in the Machine Learning and Deep Learning Toolbox (MathWorks, 2018), as described later.

\section{FIELD EXPERIMENTS}

The first field site is located in Benton County, Oregon, in the Willamette Valley, which has a humid but Mediterranean precipitation regime (little precipitation during the growing season) that requires many crops to be irrigated. The EC system and weather station were installed between two $\sim 50$ ha fields irrigated by center pivots. The 22 ha and 29 ha sections of the fields directly adjacent to the sensors were planted in snap beans (Phaseolus vulgaris). To maximize the likelihood of reliable EC measurements, the station location was chosen so that the field was uniformly flat, irrigated, and planted for more than $200 \mathrm{~m}$ (100 times the measurement height) in the direction of the predominant daytime wind direction, and nearly as uniform for $200 \mathrm{~m}$ in the directions of all other wind sectors (based on ten years of wind data collected from a nearby airport weather station). During the 2017 season, the timing and amount of irrigation were inconsistent as the farmer attempted to determine an adequate schedule for the crop. Irrigation timing was based on visible crop stress and manual measurements of soil water levels; application rates were limited by soil intake rates (farm manager, Greenspring Farms LLC, personal correspondence). As a result, the observed rate of $\mathrm{ET}_{a}$ varied from $100 \%$ of reference ET in the day following irrigation to less than $40 \%$ of reference ET in subsequent days.

The data from the Oregon site used in this analysis were collected from 12 June to 4 September 2017 (85 days). For EC measurements, an IRGASON integrated sonic anemometer and open-path gas analyzer (Campbell Scientific, Logan, Utah) was mounted at $2 \mathrm{~m}$ above ground level (a.g.l.) and oriented in the dominant daytime wind direction. Additional sensors were included for comparison in the machine learning algorithm: humidity and temperature sensors at two measurement heights (HMP-60, Vaisala Oyj, Helsinki, Finland); Decagon GS3 soil water content, soil temperature, and MP2 soil water potential sensors, Decagon tipping-bucket rain gauges, and Decagon 2-d sonic anemometers (METER Group, Pullman, Wash.); a Q-7 thermopile net radiometer (Radiation and Energy Balance Systems, Seattle, Wash.); a PAR quantum sensor (Apogee Instruments, Logan, Utah); and a cup and vane anemometer (R.M. Young Co., Traverse City, Mich.). For some 2 to 3 week training periods, an NR01 net radiometer and HFP-01 soil heat flux plate (Hukseflux, Delft, The Netherlands) and two HCS2 humidity/temperature probes (Rotronic AG, Bassersdorf, Switzerland) were co-located with the Q-7 net radiometer and HMP60 thermo-hydrometers, respectively, to cross-validate the corresponding sensors. A complete description of this field experiment is provided by Kelley and Pardyjak (2019).

Eddy-covariance measurements were also taken at three sites located on flood-irrigated agricultural land in California's Central Valley, spanning northern to southern regions during the late summer of 2019. These stations were co-located with stations in the CIMIS network that measure hydro-meteorological variables used to calculate potential ET for use by growers throughout the state. For all stations, fastresponse turbulence measurements were sampled at $20 \mathrm{~Hz}$, while slow-response sensors were sampled every $20 \mathrm{~s}$ and then averaged and recorded every $60 \mathrm{~s}$.

The northernmost station in California was located near Biggs over periodically grazed pastureland with a homogeneous fetch of approximately $180 \mathrm{~m}$ to the southeast and 350 $\mathrm{m}$ to the northwest, the two dominant daytime wind directions during late summer. This station was co-located with the Biggs CIMIS station (installed approx. $2.5 \mathrm{~m}$ to the north). Eddy-covariance measurements were made with an IRGASON mounted at $2.46 \mathrm{~m}$ a.g.l., while slower-response measurements were made with EE-181 temperature and relative humidity probes in non-aspirated radiation shields 
(Campbell Scientific) at 3.50 and $1.82 \mathrm{~m}$, an SP-110-SS pyranometer (Apogee Instruments), an NR-LITE-2 net radiometer (Kipp \& Zonen, Delft, The Netherlands), and an SI-111 infrared thermometer (Apogee Instruments). All data from this station were sampled and logged by a CR3000 micrologger (Campbell Scientific). The data used in this analysis were collected at Biggs from 8 August to 6 November 2019 (91 days).

Approximately 75 miles south of Biggs in the Central Valley, a second station was deployed in Dixon, California, co-located with the Dixon CIMIS station (approx. $2.5 \mathrm{~m}$ to the northwest). The site was also characterized by periodically grazed pastureland and had a homogeneous fetch of approximately $700 \mathrm{~m}$ to the southwest in the predominant daytime wind direction for late summer. The station was equipped with a CR6 datalogger with a CDM-A116 analog input module (Campbell Scientific), two IRGASONs (at $2.21 \mathrm{~m}$ and $4.22 \mathrm{~m}$ a.g.1.), two HMP-155A temperature and relative humidity sensors with radiation shields (Vaisala) at $2 \mathrm{~m}$ and $4 \mathrm{~m}$ a.g.l., a CNR4 four-component radiometer (Kipp \& Zonen), two HFP01-L soil heat flux plates (Hukseflux) at $0.08 \mathrm{~m}$ below the surface and $0.5 \mathrm{~m}$ apart, four 105E-L soil temperature thermocouple probes (Campbell Scientific), two at $0.02 \mathrm{~m}$ and 2 at $0.06 \mathrm{~m}$ below the surface, and two CS655 soil water content reflectometers (Campbell Scientific) at $0.05 \mathrm{~m}$ and $0.15 \mathrm{~m}$ below the surface. The data used in this analysis were collected at Dixon from 30 July to 8 October 2019 (71 days).

The southernmost station in California was located in Parlier at the Kearney Agricultural Research and Extension Center. This EC station was deployed on a 2 ha $(5 \mathrm{ac})$ alfalfa plot, approximately $500 \mathrm{~m}$ southwest of the Parlier CIMIS station due to a restrictive fetch at the CIMIS station plot. The station was situated on the alfalfa plot such that it had an approximate homogeneous fetch of $150 \mathrm{~m}$ in the predominant daytime wind directions (southeast and northwest) with the exception of a narrow, dirt farm road approximately $50 \mathrm{~m}$ northwest of the station. This station had an EC-150 (Campbell Scientific), and a CSAT sonic anemometer at $2.02 \mathrm{~m}$ a.g.l. for EC measurements. Slow-response measurements of temperature and relative humidity were taken at $2.02 \mathrm{~m}$ and $3.45 \mathrm{~m}$ from two EE-181 sensors (Campbell Scientific) with radiation shields and the four components of net radiation (i.e., downwelling shortwave and longwave and upwelling shortwave and longwave radiation) from an SN500 net radiometer (Apogee Instruments). All data were sampled and logged with a CR1000x datalogger (Campbell Scientific). The data used in this analysis were collected at Parlier from 27 July to 28 October 2019 (94 days).

\section{DATA HANDLING AND EDDY-COVARIANCE (EC) Flux Calculation}

To ensure representative ET measurements, standard EC corrections and data quality procedures (Foken et al., 2012), 2-D coordinate rotations (Wilczak et al., 2001), and density corrections (Leuning, 2007; Webb et al., 1980) were employed. A phase space method of despiking was also employed (Kelley and Higgins, 2018). Eddy-covariance measurements of ET were calculated for averaging periods ranging from 15 to $60 \mathrm{~min}$. The measured net radiation, soil heat flux, and sensible and latent heat fluxes were used to evaluate closure of the surface energy budget and assess periods for which to exclude data. Limited gap filling was required for short periods (typically not exceeding one averaging period and totaling less than $5 \%$ of all data). Gaps created by removing data were linearly interpolated for calculating cumulative ET.

The local alfalfa reference ET $\left(\mathrm{ET}_{r}\right)$ was calculated using the ASCE-EWRI Penman-Monteith equation (Allen et al., 2005; Jensen and Allen, 2016) from measured downwelling shortwave radiation, soil heat flux, air pressure, temperature humidity, and wind speed. $\mathrm{ET}_{r}$ was used to approximate potential ET, identify variability in daily irrigation requirements, and identify periods when ET was limited by water availability rather than available energy. $\mathrm{ET}_{r}$ was also used in combination with single crop coefficients to compare crop ET with machine learning predictions of actual ET. The single crop coefficient method was used because it is a practical tool for estimating crop ET without requiring additional supporting information, and it is the standard method for estimating crop water requirement in irrigation scheduling software such as provided by $\mathrm{AgWeatherNet.} \mathrm{Established} \mathrm{crop}$ coefficients were obtained from the AgriMet website (https://www.usbr.gov/pn/agrimet/cropcurves/crop_curves. html) or were adopted from earlier lysimeter studies based on planting date and crop development (Allen and Wright, 2002) and adjusted to the specific crop and planting dates in the case of the Oregon field experiment.

For data from the California sites, EddyPro v7.0.4 was used to calculate turbulent fluxes using data acquired at the Parlier, Biggs, and Dixon sites. The EC systems collected 20 $\mathrm{Hz}$ records. Discontinuities from swapping memory cards and missing data in general were replaced with non-numbers (NaNs) to fill data gaps and maintain time series continuity. Turbulent fluxes were calculated for $30 \mathrm{~min}$ intervals. The flagging policy for quality checks was based on a numbering system (Foken et al., 2005). Raw data corrections included the double rotation tilt correction method (Aubinet et al., 2012), time lag detection by covariance maximization (Fan et al., 1990), WPL density correction (Webb et al., 1980), removal of spikes (at 1\% threshold), and replacement by linear interpolation (Vickers and Mahrt, 1997). Correction of high-pass filtering effects followed the spectral corrections described by Moncrieff et al. (2005), and the fully analytic spectral correction method was used to correct for low-pass filtering effects (Massman, 2000). Using conservative estimates, quality control procedures removed less than $1 \%$ of the data in a given $30 \mathrm{~min}$ segment for up to the 95 th percentile of total segments. Extreme outliers can have greater removal rates, but most outliers reach only about $2 \%$ or less, and the total number of removed points represented less than $0.085 \%$ of the raw vertical wind velocity and water vapor concentration data, whose covariance defined the water vapor flux from the surface and hence, ET.

\section{MACHINE LEARNING IMPLEMENTATION}

The quality-controlled (but otherwise uncorrected) EC measurements and weather sensor data were imported and processed in Matlab, and the machine learning analysis used the Neural Network and Deep Learning Toolbox 
(MathWorks, 2018). A simple three-layer network (with two layers of 4 to 12 nodes and one single-node output layer) was trained using the Bayesian regularization backpropagation algorithm, which uses Levenberg-Marquardt optimization (Beale et al., 2016). This algorithm is suited to moderate-size datasets as were used in this study. Initially, the machine learning methods employed here (in single iterations) were developed as described in a previous study (Kelley and Pardyjak, 2019). The structure of an ANN is built of nodes (also called neurons). Each node is comprised of weighting and bias vectors and a transfer function that control the translation of input parameters to outputs. In the training process, the functional contribution of each input parameter is changed by assigning weighting and biases at each node and comparing the output against the training dataset. The network is randomly initialized from a subset of training data (in this case, a matrix of time-series records of weather sensor data), and uses feedback from the control estimate (in this case, ET measured by EC) to minimize error according to an assigned statistic (in this case, MSE was the learning statistic used in backpropagation). From random initial conditions, training proceeds by iterating and minimizing the difference between the control ET measurement and the value predicted by the neural network. In the Matlab toolbox, the user specifies the data input, training data, and algorithms for optimizing the ANN. Processing occurs in an intuitive user interface that also allows plotting the results and evaluating the robustness of the resulting solution. Every iteration of the ANN is randomly initialized, so two ANNs trained on identical data will produce slightly different outputs. As the input data (i.e., either the sensor data or the number of iterations) are reduced, the resulting output network can become overfitted to the small data set (Bowden et al., 2005; Srivastava et al., 2014). ANN predictions of ET resulting from overfitted networks become more scattered and do not reproduce expected patterns, such as the diurnal variability in flux magnitude.

Machine learning training was performed iteratively while varying the number of input parameters, varying the duration of the training data, and by selecting subsets of training data from different time periods in each dataset. Initially, two contiguous weeks of training data were selected at random, and subsequent training periods of 1 to 21 days were used. The predicted $\mathrm{ET}_{a}$ results were compared to the half-hour $\mathrm{ET}_{a}$ measured by EC during all half-hour periods. The resulting time series of latent heat flux was then used to calculate a cumulative daily evaporation (in $\mathrm{mm}$ depth) from three methods: (1) direct measurement of $\mathrm{ET}_{a}$ by EC, (2) the ASCE-EWRI standardized reference ET equation $\left(\mathrm{ET}_{r}\right)$ and single crop coefficients $\left(K_{c}\right)$, and (3) the machine learning prediction based on sensor data (denoted $\mathrm{ET}_{\mathrm{ANN}}$ ). The resulting daily and cumulative ET time series were compared by linear regression. The correlation coefficient $\left(\mathrm{R}^{2}\right)$ and root mean squared error (RMSE) were used to compare the resulting scatter between the measured and predicted $\mathrm{ET}_{a}$ for all data (inclusive of the periods used to train the ANN). The coefficients of regression between the measured and predicted $\mathrm{ET}_{a}$ generally were not useful in describing the results, as most predictions were not uniformly distributed. A successfully trained network for a specific training subset was indicated when the $\mathrm{R}^{2}$ and RMSE of the predicted $\mathrm{ET}_{\mathrm{ANN}}$ were comparable to the same statistics comparing $\mathrm{ET}_{a}$ to $\mathrm{ET}_{r}$. In other words, successful training needed to produce a prediction at least as robust as could be found with the ASCE-EWRI equation, with both methods compared against the measured actual ET.

The workflow for training the neural network and estimating ET with the resulting ANN was as follows:

1. Half-hour mean values of each input parameter were calculated, corresponding to the averaging periods used for calculating actual ET with the EC method. For CIMIS data, which are provided at hourly intervals, 30 min values were linearly interpolated. Time of day was determined from the data record time stamp. The ratio of actual to reference ET was calculated for all daytime records (equivalent to a single crop coefficient). Closure of the surface energy budget (SEB) was calculated at each step, using direct measurements of net radiation and soil heat flux where available (i.e., soil heat flux, sensible and latent heat flux were subtracted from net radiation). At sites where four-component radiometers and/or soil heat flux plates were not available, net radiation and soil heat flux were approximated following Allen et al. (1998).

2. Reference ET values were obtained from nearby AgriMet or CIMIS station records. For the Oregon site, reference ET was calculated using the Penman-Monteith equation using an alfalfa reference, i.e., $\mathrm{ET}_{r}$ (Jensen and Allen, 2016; Walter et al., 2000). Clear sky radiation $\left(R_{s o}\right)$ was calculated following Allen et al. (1998), and downwelling shortwave radiation $\left(R_{S}\right)$ was corrected at the site and for periods in which $R_{s}$ appreciably differed from $R_{s o}$, following Appendix D of Walter et al. (2005). For the Oregon site, a daily site-specific crop coefficient was obtained by adapting the alfalfa reference crop coefficient $\left(K_{c}\right)$ for snap beans from Allen and Wright (2002).

3 . The network structure (nodes and layers) was specified for the ANN. The number of nodes in a single layer varied but did not exceed the number of input parameters. Networks with one or two hidden layers were employed in this study (fig. 1). The network also assigned a singlenode output layer (for the single output of $\mathrm{ET}_{a}$ ). For each training, a number of days and a starting day (e.g., 15 days starting on day 30 of the experiment) were specified, and a subset of the EC and weather sensor data was input to the ANN for training. Training proceeded automatically using the Matlab toolbox, with $90 \%$ of the 30 min data records in the training set used for training and the remaining $10 \%$ used for testing by the backpropagation algorithm. Training consisted of a random assignment of initial weights and biases in the hidden nodes, which were adjusted iteratively until the MSE between the training set and the training value of $\mathrm{ET}_{a}$ no longer improved (Beale et al., 2016).

4. Half-hour averages for the entire data record (including the training period) were then input to the trained ANN model, which estimated a time series of predicted actual ET. The $\mathrm{R}^{2}$, RMSE, and linear regression coefficients were calculated for $30 \mathrm{~min}$ and total daily crop ET $\left(K_{c} \times\right.$ $\left.\mathrm{ET}_{r}\right)$ and ANN-estimated actual ET, compared to the ET measured by the EC method. 


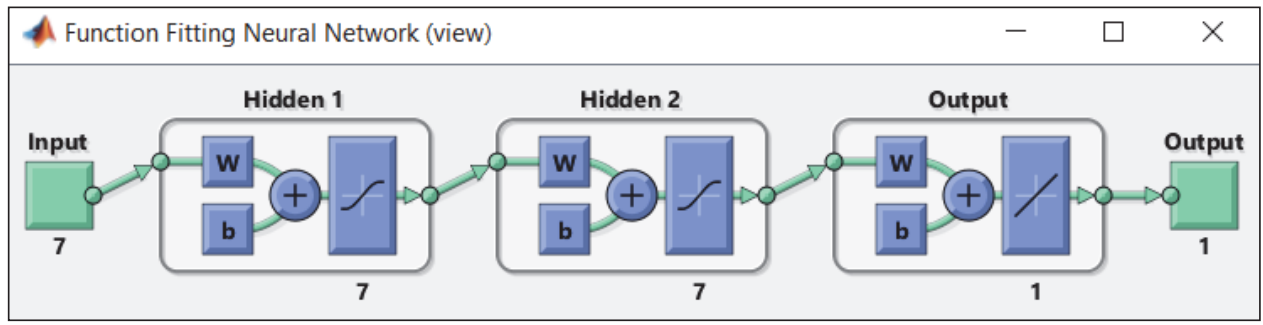

Figure 1. Diagram of a typical neural network used in this study showing two hidden layers with seven nodes each, corresponding to the seven input parameters. Each node consists of weighting (w) and bias (b) vectors and a transfer function, noted in the hidden layers as a log-sigmoid function. Training was conducted on a subset of 30 min records of weather and other sensor data, using the 30 min EC data as a control estimate of ET for the supervised learning algorithm. The trained network was then used to estimate ET for all 30 min weather and sensor data for a given site, and the resulting estimate was compared against the measured EC data (diagram generated using Matlab; MathWorks, 2018).

5. Training was repeated for each network arrangement (number of nodes, training time, and input parameters) to determine a minimum set (number of sensors and training duration) required to train networks that could reliably reproduce the observed diurnal and seasonal variability in actual ET. For evaluating ensemble solutions, 100 neural networks were trained iteratively (each instance was an independent training with identical input parameters).

\section{RESULTS AND DISCUSSION}

The four sites presented in this study demonstrated a wide range of patterns in seasonal and daily crop water demand. The EC measurement of actual ET confirmed the expected patterns in each case. At the Oregon site, the irrigator reported that the irrigation schedule was changed repeatedly throughout the season, e.g., $25 \mathrm{~mm}$ ( $1 \mathrm{in}$.) application once per week, $13 \mathrm{~mm}(1 / 2 \mathrm{in}$.) applied every third day, etc., to address challenges in irrigating the field characterized by low intake rates and low to moderate water holding capacity (farm manager, Greenspring Farms LLC, personal communication). This was confirmed by actual ET measured by EC, which matched reference ET on days when irrigation occurred but typically was $30 \%$ to $40 \%$ of reference, indicating potential drought stress in the crop (fig. 2). The evaporation rate predicted by the reference ET and crop coefficient, as reported by the publicly available data and calculated using the on-farm weather data, was less than the measured $\mathrm{ET}_{a}$ during the first three weeks following germination (fig. 3).

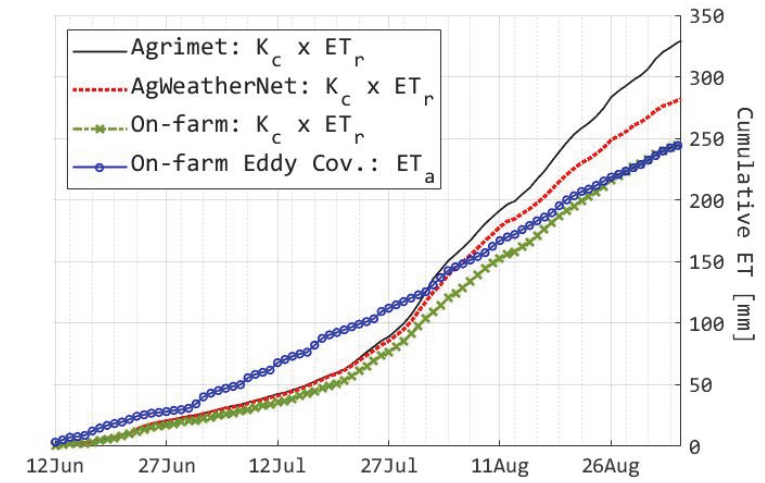

Figure 3. Cumulative ET from local and on-farm weather data. Actual ET $\left(\right.$ ET $\left._{a}\right)$ was measured using the eddy-covariance (EC) method. Alfalfa reference ET (ET $r$ ) was determined using the ASCE-EWRI Penman-Monteith method for 30 min periods (matching the EC averaging period) and summed for daily time steps. Daily crop coefficients for snap beans $\left(K_{c}\right)$ were based on days since planting and were adapted based on alfalfa reference crop coefficients from Allen and Wright (2002).

An irrigation prescription based on any of these reference ET estimates would lead to a deficit during early crop development, even if the total requirement was met or exceeded over the entire season. The on-farm $\left(K_{c} \times \mathrm{ET}_{r}\right)$ method matched cumulative season total $\mathrm{ET}_{a}$, but all reference ET methods underestimated the daily $\mathrm{ET}_{a}$ rate until mid-July, and then overestimated the daily rate during late July and August (fig. 3 ). On days when irrigation occurred (visible on day 20, day 27, day 31, etc., in fig. 2), actual ET approached or slightly

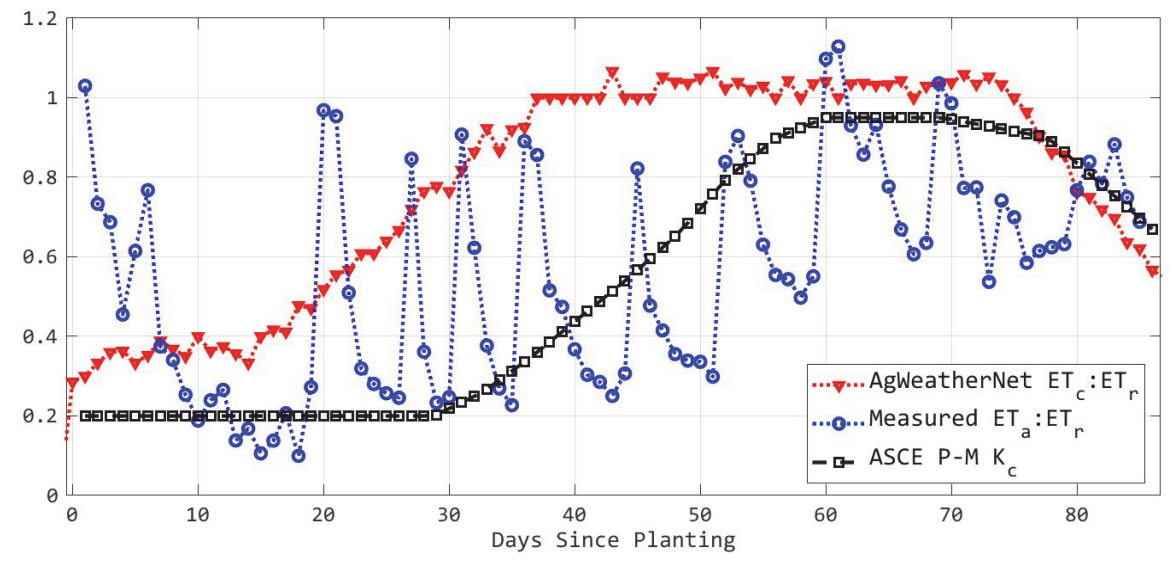

Figure 2. Daily crop coefficients for snap beans (squares, from Allen and Wright, 2002), daily $\mathbf{E T}_{c}: \mathrm{ET}_{r}$ ratio measured at the closest network station (triangles), and $\mathrm{ET}_{a}: \mathrm{ET}_{r}$ ratio measured by eddy-covariance (circles) at the Oregon site during 2017. 
exceeded $\mathrm{ET}_{r}$. Subsequently, actual ET returned to a range of $30 \%$ to $40 \%$ of reference ET.

At the two pasture sites (Biggs and Dixon), an expected end-of-season trend was observed, with daily ET decreasing consistently with the shorter day length and less solar irradiation (fig. 4a shows results at Dixon). In contrast, the alfalfa at the Parlier site also showed a reduction in ET during periods following cutting (harvest) of the crop, with a gradual return toward full ET as the canopy re-established (fig. 4b). ET at the Parlier site also demonstrated the downward endof-season trend in daily ET throughout the July to October period.

Actual ET varies in diurnal and seasonal patterns, which are largely driven by available energy. Because the P-M equation is derived from conservation of energy (Penman, 1948), estimates such as the P-M equation are parameterized to adjust second-order effects such as crop and soil response to water availability. These effects are non-linear, confounding a general analytic solution and requiring empirical calibrations, such as the development of crop coefficients. While evaluating ET on a daily time scale, a simple parameterization based on phenology, days since planting, or other factors can resolve these non-linear patterns. However, when estimating ET over shorter time periods, more complex patterns can emerge. In figure 5, the unweighted, average 30 min ratio was used to approximate a site-specific crop coefficient applied to the reported CIMIS reference ET in calculating cumulative ET. In this case (alfalfa), the site-specific crop coefficient was calculated as 0.53 , which was at least partly due to the inclusion of periods when alfalfa was

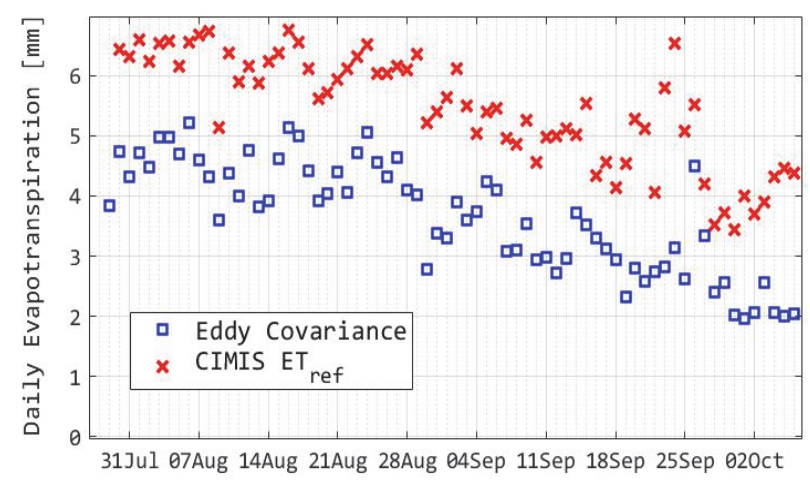

(a)

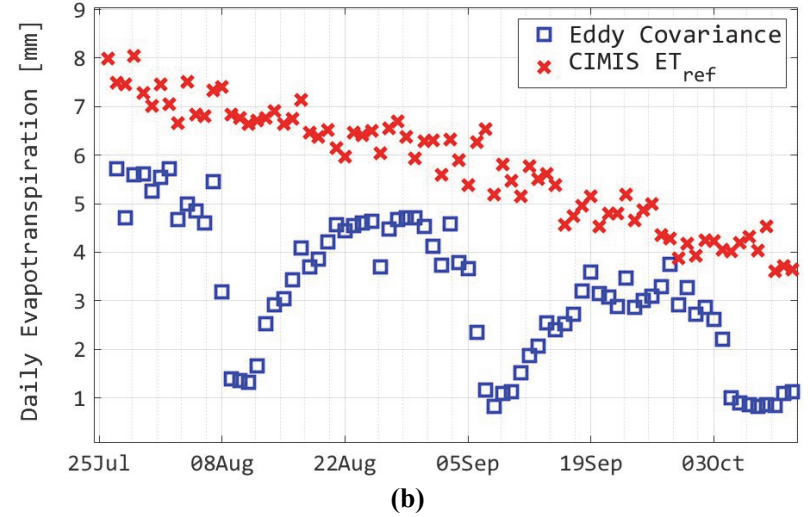

Figure 4. Time series of total daily ET at the (a) Dixon and (b) Parlier sites in 2019. Squares indicate actual ET determined by eddy-covariance, and " $x$ " symbols indicate daily estimated reference ET totals from hourly CIMIS records.

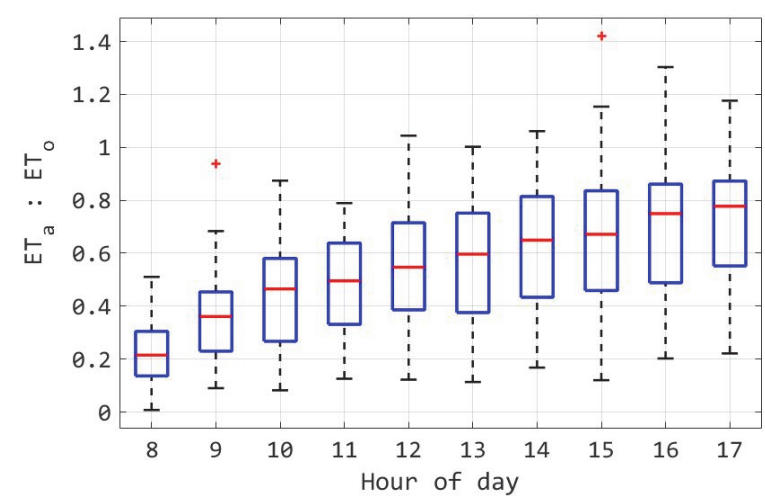

Figure 5. Total $30 \mathrm{~min}$ ratio of actual ET $\left(\mathrm{ET}_{a}\right)$ to reference ET $\left(\mathrm{ET}_{r}\right)$, the site-specific crop coefficient, for each hour during the day at the Parlier site. Lines in boxes indicate medians, boxes indicate second and third quartiles, and whiskers indicate first and fourth quartiles. Plus markers (+) indicate a very small number of statistical outliers.

harvested and there was little actual ET. While these secondorder effects are typically site- and crop-specific, they tend to be consistent for a specific application. Neural networks are able to reproduce non-linear effects when estimating actual ET and reproduce the cumulative and instantaneous ET. The simplest application of this approach, supervised learning, is feasible if the training set includes a reliable estimator of the output (fig. 6).

The ANN training was able to reproduce actual ET in the four field experiments. With appropriate selection of training data to include a representative sample of the variability in actual ET and other input variables, the ANN was able to estimate actual ET (compared to EC measurements) more accurately than the P-M equation with a single crop coefficient (fig. 6a), as indicated by an increase in $\mathrm{R}^{2}$ and reduction in RMSE (fig. 6b). Compared to EC, the P-M estimate did not reproduce the daily variability in actual ET $\left(\mathrm{R}^{2}=0.21\right.$, RMSE $\left.=1.5 \mathrm{~mm} \mathrm{~d}^{-1}\right)$. A neural network can potentially reduce RMSE and improve fidelity in estimating daily ET rates, which irrigators can exploit for scheduling (fig. 6b). For all four field experiments, the most robust ANN estimates required two weeks of training data, although the performance of the ANN method was better for the California sites with three weeks of training data. The ANN estimates were not particularly sensitive to the number of input parameters (weather sensor data), and in all ANN results shown here, a minimum set of the following parameters were used: air temperature and humidity, downwelling (incoming) solar radiation, wind speed, and time of day. Inclusion of additional parameters directly related to evaporative flux, temperature and humidity gradients, and soil heat flux were included in some iterations but did not make measurable differences in the robustness of the resulting training outputs. Because temperature and humidity were measured at two heights at the Oregon site, they were included in most training iterations and may have contributed to stronger correlations between the $\mathrm{ET}_{a}$ resulting from shorter training times. For the California sites, weather data from the nearby CIMIS stations supplemented (or replaced) on-site sensor data, with little observable effect apart from anecdotally improved estimates with shorter training times. 


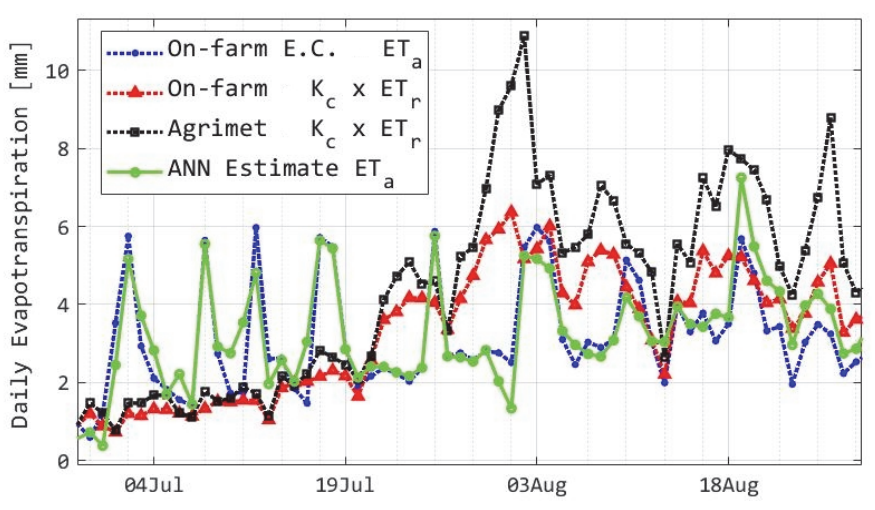

(a)

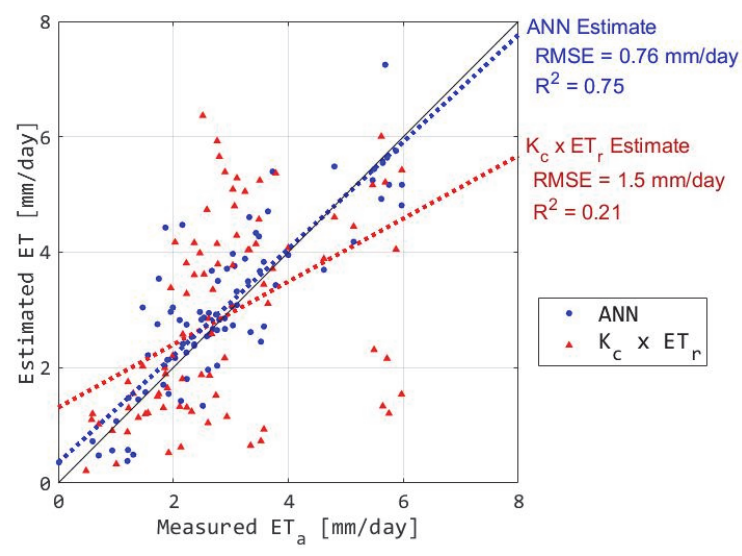

(b)

Figure 6. Results from one arbitrarily selected ANN trained for 14 days at the Oregon site using seven input parameters (air temperature and humidity at two heights, downwelling shortwave radiation, wind speed, and time of day).

From the perspective of providing robust and useful information to irrigators, the correspondence between the ANN estimates and EC measurements on 30 min intervals has little practical meaning. Cumulative ET, in areal depth, is directly related to crop water demand, as shown in figure 7. The daily consumptive water demand, as shown here, is typically more useful in irrigation scheduling than $30 \mathrm{~min}$ flux estimates or sensor data reported on 30 min intervals, as shown in figure 8.

Previous work with ANNs to estimate actual ET showed that the network is sensitive to the representativeness of the input parameters (compared to the global data) and not particularly sensitive to small training sets (Kelley and Pardyjak, 2019). For the Oregon site, highly variable conditions occurred on 2- to 5-day cycles, corresponding to the irrigation schedule. This meant that when the training data were drawn from just a few consecutive days, the ANN responded to a much wider range of conditions (fig. 2) than would be typical under more uniform, well-watered conditions. For the California sites, the range of variability in actual ET (and other environmental parameters) was more uniform and changed more slowly over longer time periods. As

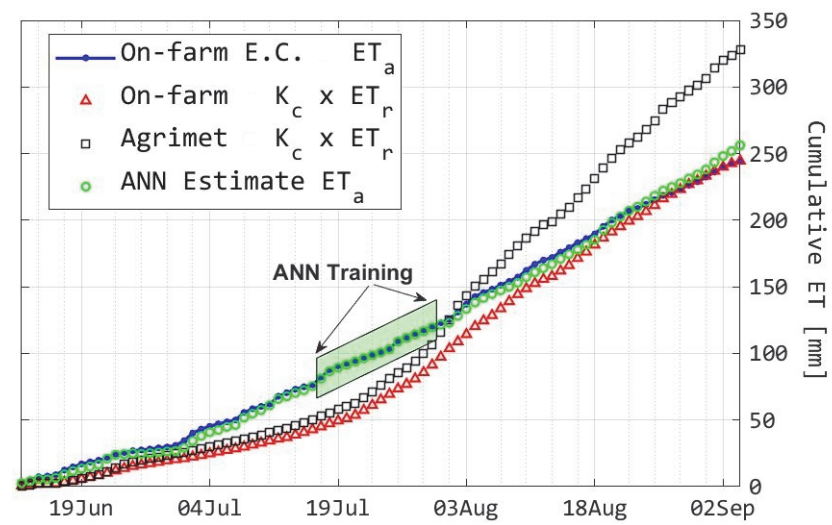

Figure 7. Cumulative ET at the Oregon site estimated with the four methods described in the text. The AgriMet P-M estimate used the re-

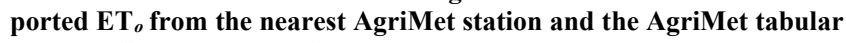
crop coefficient. The on-farm P-M estimate used the same equation with on-farm sensor measurements and a locally calibrated crop coefficient. The ANN estimate was based on training data from a two-week period (shaded box). a result, the ANNs trained over periods shorter than 14 days were not as robust, and sequential training of the ANNs resulted in low correlation with the actual ET. Training periods as long as 21 days were more robust, but the performance of the ANNs was still sensitive to the range of actual ET during the measurement period (fig. 8). Note that 14 days and 21 days of training data, both starting at day 15 , generated similar results (figs. 8a and 8c). In contrast, the ANN trained for 21 days starting at day 45 , when the range of ET was smaller, estimated ET with considerably more scatter compared to the measured $\mathrm{ET}_{a}$ (fig. 8b).

One challenge to applying machine learning more broadly is a lack of information about the generality of the resulting solutions. Here we have shown that the ANN method can estimate site-specific ET, given that the training data include sufficient parameter variability to represent the range of true conditions. Unlike when using an analytic equation based in first-order physical principles, such as the EC method or the P-M equation, estimating the influence of any specific environmental parameter is beyond the scope of this study. As a simple evaluation of the generality of the ANN solutions, we applied the network solution validated at one site to other sites with comparable data. As an example, figure 9 shows the cumulative ET measured by EC (circles), the cumulative ET calculated with a site-specific crop coefficient and the CIMIS reference ET (stars), reference ET (triangles), and actual ET estimated by the ANN (squares). An ANN was trained using 21 days of data at the Dixon site (fig. 9a). Data from the Biggs site was then input into the same network, resulting in a less accurate but still reasonable cumulative flux (fig. 9b). The resulting ANN underestimated actual ET, but the surprising result is that the ANN still produced an estimate closer to the measured ET than the results from applying a site-specific crop coefficient to the nearby CIMIS reference ET. These two sites are similar (irrigated pasture, same year, similar time of year), so this finding suggests that the same general factors operate at both sites.

A robust machine learning method will also be repeatable with an acceptable level of variation between each application of the learning algorithm, with reliable estimates of the output parameters and the concomitant uncertainty. Because neural networks are trained with a random initialization of 

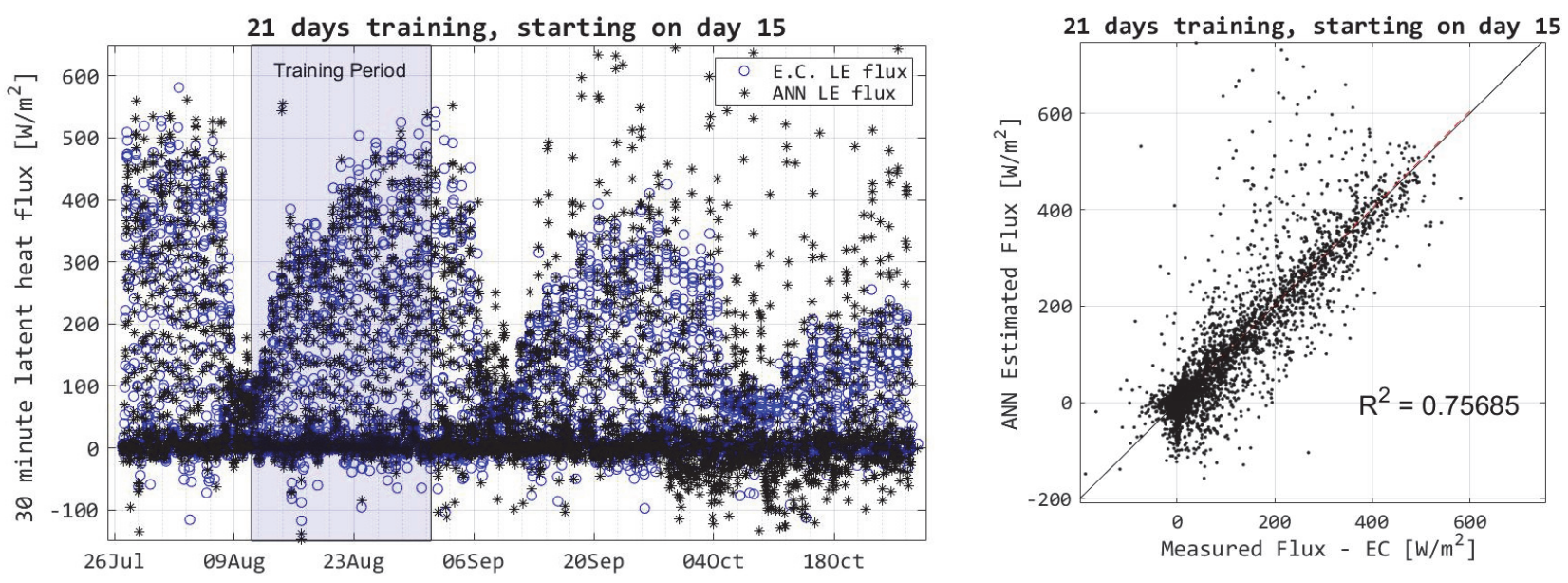

(a)
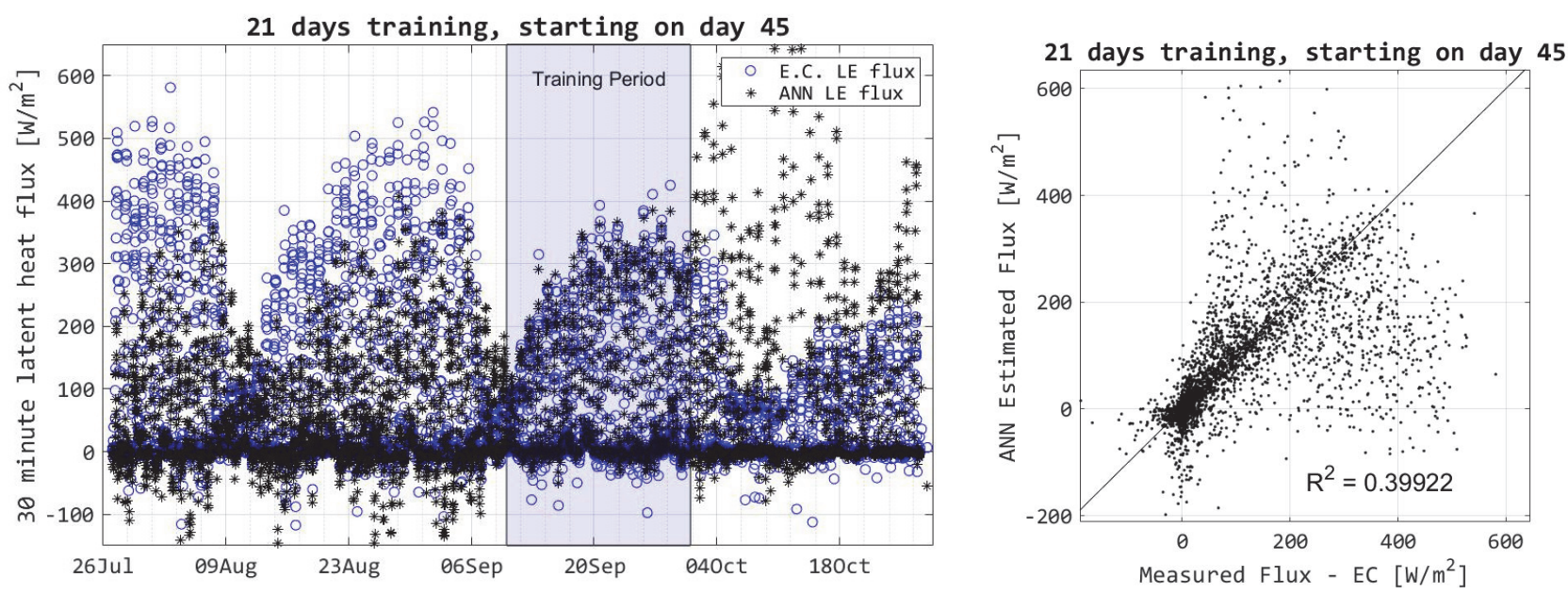

(b)
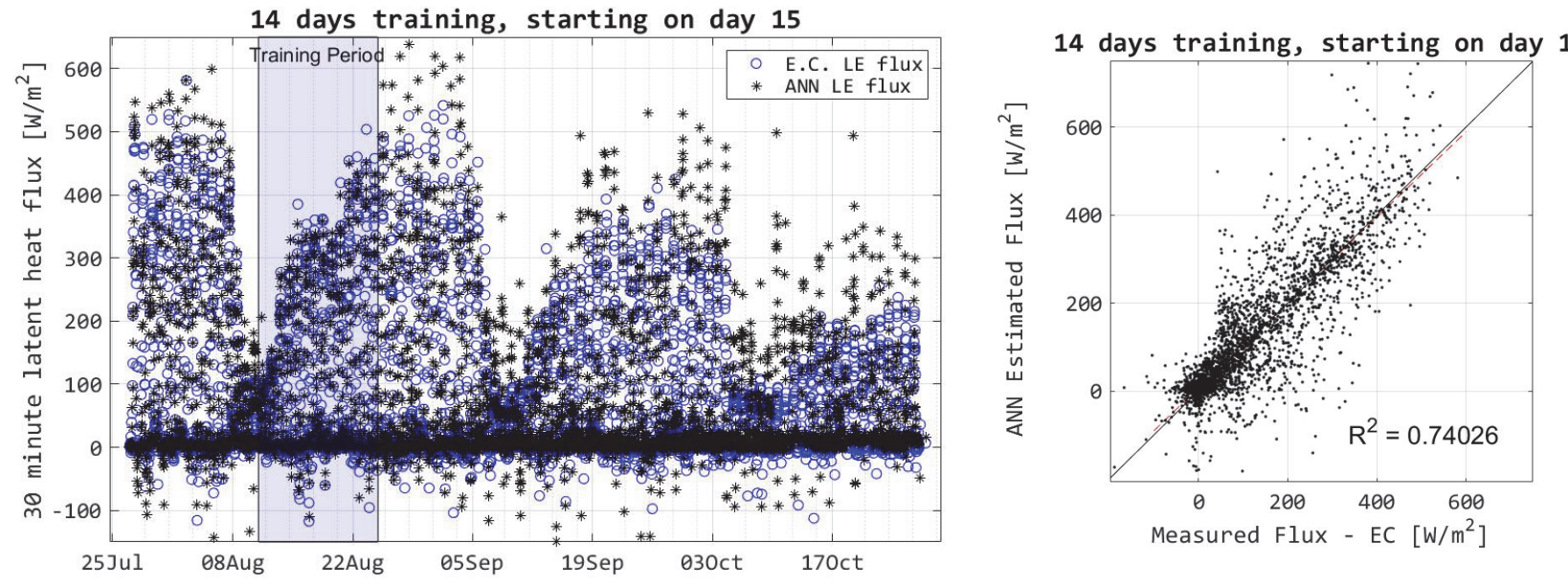

(c)

Figure 8. Three training iterations of ANN estimates at the Parlier site. Variability in the ET used as training data increases the scatter of the resulting 30 min ET estimate (training periods are shown as shaded boxes in left plots).

the weighting and bias functions, we generated large ensembles of trained ANNs to visualize the range of uncertainty associated with a given size of the input data used in training. As shown in figure 10, the cumulative ET was estimated by an ensemble of 100 neural networks (plotted as the mean \pm 1 standard deviation). Although each member of the ensemble would not typically accumulate error for every day of the entire season, neither is error unbiased for each ANN output; therefore, the cumulative bounds shown are a moderately conservative estimate of the cumulative uncertainty for a specific set of training parameters. It is evident that a 14-day training period reduced the range of potential ET estimates, although in this specific case, the ensemble average from ANNs trained for seven days more closely matches the EC 
Dixon ET indicating ANN training period

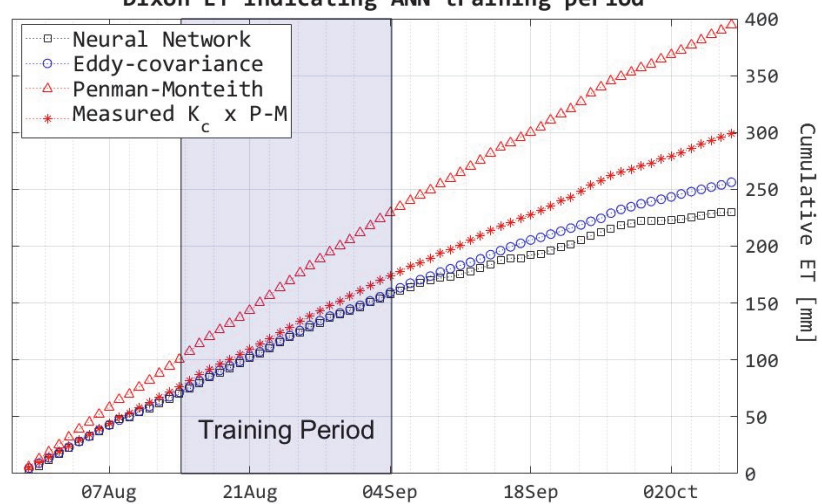

(a)

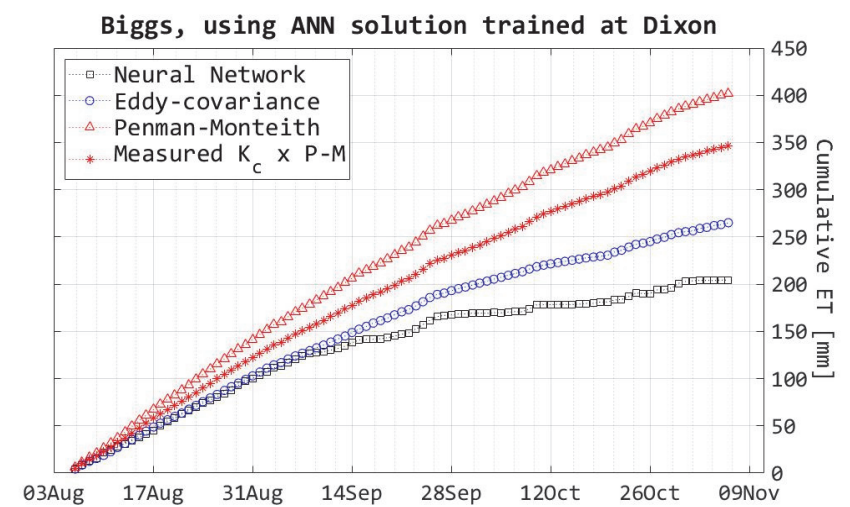

(a)

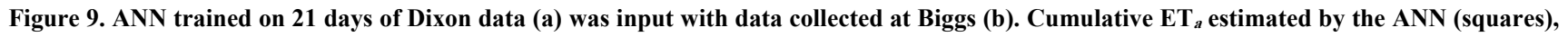
measured ET (circles), and cumulative $\mathbf{E T}_{r} \times K_{c}$ (stars) was reported by the adjacent CIMIS station for each location.

Ensemble of ANN Estimates (7 day training)

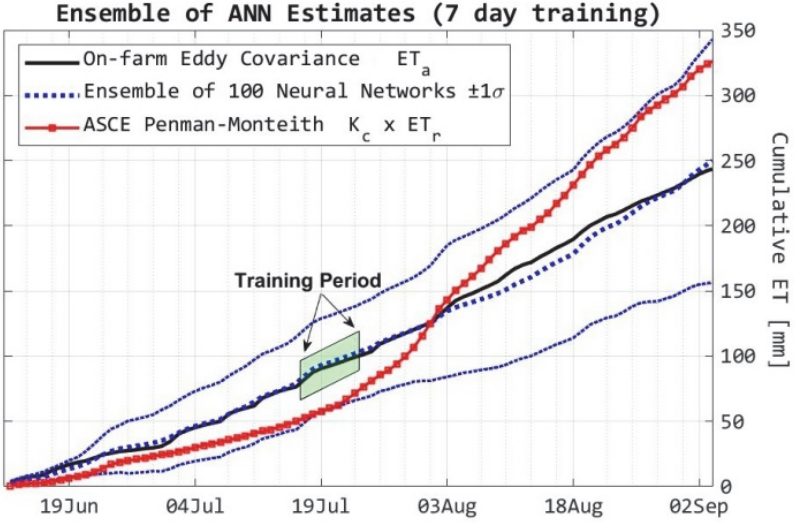

(a)

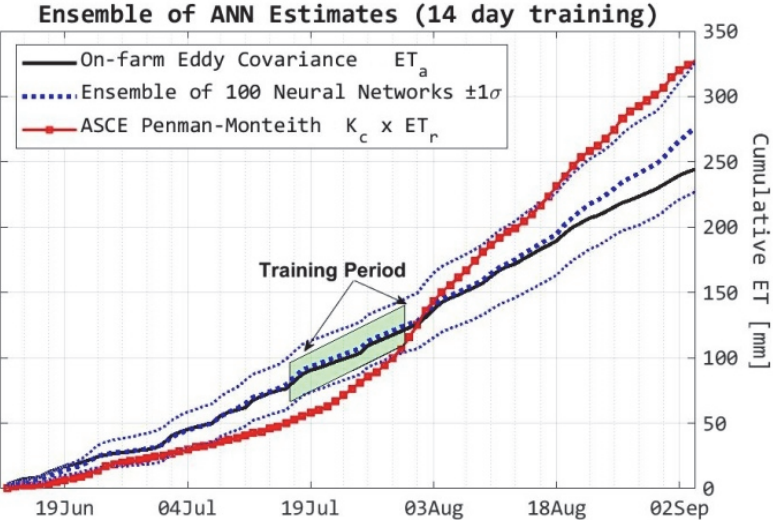

(b)

Figure 10. Ensembles of cumulative ET from 100 iterations of ANN training at the Oregon site. The heavy dashed line indicates the ensemble average, with lighter dashed lines indicating the cumulative mean \pm 1 standard deviation of the 100 ensemble members. The square symbols indicate the crop coefficient adjusted reference ET taken from the closest AgriMet station, and the solid black line indicates the EC measurement of ET used to train the neural networks.

data used as the control estimate. This supports previous observations that an ANN estimate is sensitive to the actual conditions under which the network was trained. This is evident for the 14-day training period (shaded area in fig. 10b), a period that spans a broader range of conditions that resemble the late season. The resulting ET rate more closely matches the rate of P-M ET after 18 August, which is also when the ensemble ET rate departed from the observed $\mathrm{ET}_{a}$. Prior to 18 August, a heavy irrigation was applied once every 7 to 8 days; after August 18, irrigation was applied at a lower rate every third day (farm manager, Greenspring Farms LLC, personal communication).

As an additional description of the error inherent in estimating ET with the ANN, the $\mathrm{R}^{2}$ and RMSE were calculated for daily ET values, compared to actual ET. Using total cumulative ET as a conservative estimate of effective total error for each ANN model, the $\mathrm{R}^{2}$ and RMSE were plotted against the cumulative ET for each of the 100 iterations (fig. 11). For reference, figure 11 also shows the $\mathrm{R}^{2}$ and RMSE for daily $K_{c} \times \mathrm{ET}_{r}$ values at both the on-farm and AgriMet stations. Compared to the actual ET (vertical dashed lines), nearly all ANN iterations improved fidelity in reproducing daily ET values, with lower RMSE and higher $\mathrm{R}^{2}$. As shown in figure 6 , the on-farm Penman-Monteith estimate accurately predicted the crop ET for the entire season, but the ANN was able to predict the daily ET much better, providing critical information for irrigators in making daily allocation decisions. As expected, the 14-day training more consistently produced a reliable estimate by reducing the probable error in the estimation output of the neural network.

\section{CONCLUSIONS}

Direct monitoring of actual evapotranspiration for prescribing efficient irrigation application is theoretically attractive to increase water use efficiency, prescribe sufficient application rates, and schedule irrigation with minimal loss. However, direct measurement of actual ET is expensive, technically and practically challenging, and sometimes incompatible with farm operations. Direct measurement of actual ET is fundamentally challenging due to the complexity and variability of the underlying phenomena. While there is a substantial body of research to guide irrigators in determining reference ET, and most U.S. regions have networks in 


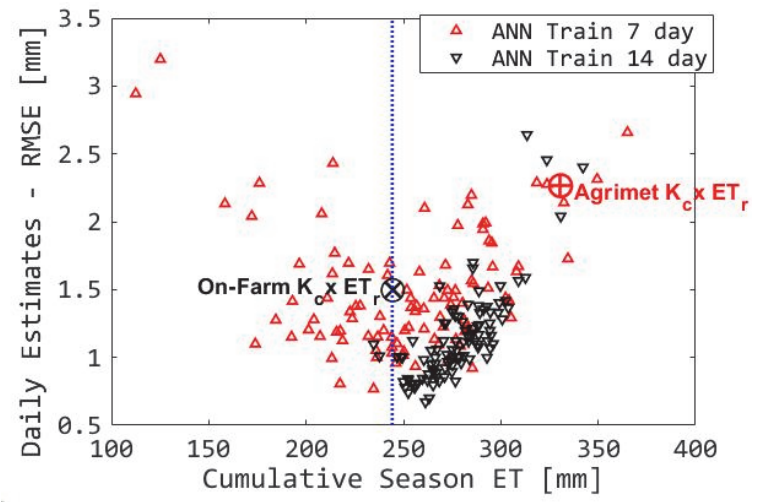

(a)

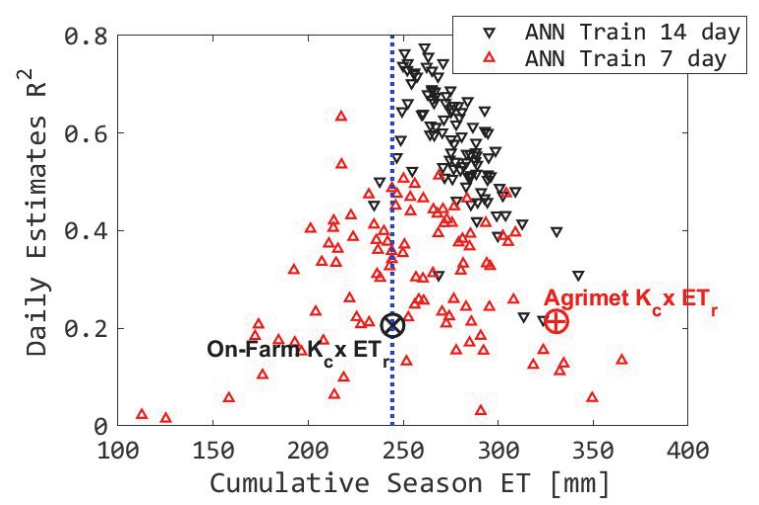

(b)

Figure 11. Error estimates for 100 training iterations showing the (a) RMSE and (b) $\mathbf{R}^{2}$ values for the corresponding AgriMet weather network station $(\oplus)$ and on-farm P-M estimates $(\otimes)$ are shown, demonstrating the ability of the neural networks to improve the fidelity of daily ET estimates. Vertical dashed lines indicate the control estimate of cumulative ET as measured by eddy-covariance.

place that provide hourly and daily estimates of reference ET, using these techniques effectively requires an investment of time and skill that is not feasible for many irrigators. At the same time, researchers have developed techniques such as eddy-covariance (EC) that are accurate but which require skill and significant labor to implement. Beyond this, it is difficult to translate these data into practical, site-specific information that is useful to the average irrigator in making scheduling decisions.

By leveraging affordable, publicly available data and low-cost sensors, machine learning offers the possibility to expand the monitoring of actual ET to a broader audience of end-users. For example, the application in this study implemented EC for training on-farm weather stations to report actual ET. This suggests possible applications of the EC method in practical monitoring. It is feasible to implement similar co-located monitoring, which would allow professionals such as Extension agents and agro-meteorology network staff to provide regionally specific ANNs that estimate actual ET. These ET estimates would complement existing reference ET methods and could facilitate broader adoption of ET-based irrigation scheduling. More generally, it is also likely that any reliable estimate of crop water requirement could be used in lieu of EC, so that other methods, such as the Bowen ratio, lysimeters, and soil water monitoring could be integrated through machine learning. The main goal demonstrated here is to produce estimates of site- and cropspecific ET from easily measured weather parameters, rather than relying solely on empirically calibrated equations.

There are many situations in which crop coefficients are not available, and there is no straightforward way to estimate crop water requirement apart from monitoring soil water and crop status. Discrepancies in the estimates of daily ET prevent irrigators from scheduling irrigation to follow time-sensitive crop water demand and undermine confidence in scientifically ET-based estimates, soil water depletion, and crop water requirements. Under these conditions, irrigators must depend on their experience and constant manual soil and plant-stress observations to judge the timing and amount of irrigation. Examples include when growing newly developed crop varieties, when there are no nearby public agrometeorology stations, when publicly available data are unreliable or do not represent site-specific conditions, and where limited water supply necessitates deficit irrigation. In any given season, a similar constraint may prevent an irrigator from using ET data in scheduling irrigation. Extreme weather events such as drought and heat can also affect crop water demand in both the short term and over the growing season. In these cases, machine learning may offer adaptable techniques to predict crop water demand, which would not be possible with empirically derived crop coefficients. The ability of ANNs to preserve information from direct measurements can help estimate impacts to crops and help prescribe specific irrigation practices to mitigate negative consequences. This adaptability may be especially pertinent in a changing and more unpredictable climate. Machine learning offers a unique advantage in allowing the end-user to accumulate data and improve the resulting model. Furthermore, the results shown here demonstrate that machine learning may also be able to produce general, rather than simply sitespecific, models of crop water requirements, although more testing is necessary.

These results show that ANNs can be useful for leveraging available data and affordable on-farm sensors to estimate site-specific, actual ET in real time. Integration of this method into decision support tools could incentivize the adoption of precision irrigation technology by providing critical information required to improve irrigation water management, guide sustainable use of water resources, reduce risk from drought stress and underapplication, and preserve crop yields.

\section{ACKNOWLEDGEMENTS}

We would like to acknowledge support in the form of equipment, data, and creative effort from Dr. Chad Higgins (Oregon State University), Dr. Eric Pardyjak (University of Utah), and Dr. Walt Mahaffee (USDA-ARS). Oregon field staff included Taylor Vagher, Willow Walker, Johanna Alexson, Tom DeBell, Payse Smith. In Oregon, we benefitted from cooperation with Greenspring LLC. For assistance with siting in California, we thank Jeff Dahlberg and Dale Pattigan at the Kearney Agricultural Research and Extension Center, Tracy Schohr of University of California Cooperative Extension for her assistance at the Biggs station, and 
Mark Rivera, Todd Flackus, James Brigs, Steve Ewert, Bekele Temesgen, and others at the California Department of Water Resources. Thanks also to Matthew Miksch for help in the field in 2019.

We would also like to thank the diligent and thorough reviews provided by the editors and three anonymous reviewers, which allowed us to rectify several errors in the manuscript and resulted in a much better presentation of the results and conclusions.

Funding for the field studies was provided in part by USDA-AFRI Grant No. 2017-67012-26125 and by NSF Physical and Dynamic Meteorology (PDM) Grant No. 1848019.

The Matlab scripts used to parameterize the machine learning methods in this article are available on request from the corresponding author: jasonrk@uidaho.edu.

\section{REFERENCES}

Alemohammad, S. H., Fang, B., Konings, A. G., Aires, F., Green, J. K., Kolassa, J., ... Gentine, P. (2017). Water, energy, and carbon with artificial neural networks (WECANN): A statistically based estimate of global surface turbulent fluxes and gross primary productivity using solar-induced fluorescence. Biogeosciences, 14(18), 4101-4124. https://doi.org/10.5194/bg-14-4101-2017

Allen, R. G., \& Wright, J. L. (2002). Conversion of Wright (1981) and Wright (1982) alfalfa-based crop coefficients for use with the ASCE standardized Penman-Monteith reference evapotranspiration equation. Technical Note. Washington, DC: USDA-ARS. Retrieved from https://www.uidaho.edu//media/UIdaho-Responsive/Files/cals/centers/Kimberly/waterresources/Conversion-of-Wright-Kcs-

2c.pdf?la=en\&hash=EE59D20A6F6F36B8F013AE932E2005E 1258B4B97

Allen, R. G., Pereira, L. S., Howell, T. A., \& Jensen, M. E. (2011). Evapotranspiration information reporting: I. Factors governing measurement accuracy. Agric. Water Mgmt., 98(6), 899-920. https://doi.org/10.1016/j.agwat.2010.12.015

Allen, R. G., Pereira, L. S., Raes, D., \& Smith, M. (1998). Crop evapotranspiration: Guidelines for computing crop water requirements. FAO Irrigation and Drainage Paper No 56. Rome, Italy: United Nations FAO.

Allen, R. G., Pereira, L. S., Smith, M., Raes, D., \& Wright, J. L. (2005). FAO-56 dual crop coefficient method for estimating evaporation from soil and application extensions. J. Irrig. Drain. Eng., 131(1), 2-13. https://doi.org/10.1061/(ASCE)07339437(2005)131:1(2)

Allen, R. G., Walter, I. A., Elliott, R. L., Howell, T. A., Itenfisu, D., Jensen, M. E., \& Snyder, R. L. (Eds.) (2005). The ASCE standardized reference evapotranspiration equation. Reston, VA: ASCE. https://doi.org/10.1061/9780784408056

Aubinet, M., Vesala, T., \& Papale, D. (2012). Eddy covariance: A practical guide to measurement and data analysis. Dordrecht, The Netherlands: Springer Atmospheric Sciences. https://doi.org/10.1007/978-94-007-2351-1

Beale, M., Hagan, M., \& Demuth, H. (2016). Neural Network Toolbox Reference (ver. 9.1). Natick, MA: MathWorks Inc.

Bowden, G. J., Maier, H. R., \& Dandy, G. C. (2005). Input determination for neural network models in water resources applications. Part 2. Case study: Forecasting salinity in a river. $J$. Hydrol., 301(1), 93-107.

https://doi.org/10.1016/j.jhydrol.2004.06.020
Daccache, A., Knox, J. W., Weatherhead, E. K., Daneshkhah, A., \& Hess, T. M. (2015). Implementing precision irrigation in a humid climate: Recent experiences and on-going challenges. Agric. Water Mgmt., 147, 135-143. https://doi.org/10.1016/j.agwat.2014.05.018

Davis, S. L., \& Dukes, M. D. (2010). Irrigation scheduling performance by evapotranspiration-based controllers. Agric. Water Mgmt., 98(1), 19-28. https://doi.org/10.1016/j.agwat.2010.07.006

Evans, R. G., \& King, B. A. (2012). Site-specific sprinkler irrigation in a water-limited future. Trans. ASABE, 55(2), 493-504. https://doi.org/10.13031/2013.41382

Evans, R. G., LaRue, J., Stone, K. C., \& King, B. A. (2013). Adoption of site-specific variable-rate sprinkler irrigation systems. Irrig. Sci., 31(4), 871-887. https://doi.org/10.1007/s00271-012-0365-x

Fan, S.-M., Wofsy, S. C., Bakwin, P. S., Jacob, D. J., \& Fitzjarrald, D. R. (1990). Atmosphere-biosphere exchange of $\mathrm{CO}_{2}$ and $\mathrm{O}_{3}$ in the central Amazon forest. J. Geophys. Res. Atmos., 95(D10), 16851-16864. https://doi.org/10.1029/JD095iD10p16851

Foken, T., Göockede, M., Mauder, M., Mahrt, L., Amiro, B., \& Munger, W. (2005). Post-field data quality control. In Handbook of micrometeorology (pp. 181-208). Dordrecht, The Netherlands: Springer Atmospheric Sciences. https://doi.org/10.1007/1-4020-2265-4 9

Foken, T., Leuning, R., Oncley, S. R., Maüder, M., \& Aubinet, M. (2012). Corrections and data quality control. In Eddy covariance: A practical guide to measurement and data analysis (pp. 85-131). Dordrecht, The Netherlands: Springer Atmospheric Sciences. https://doi.org/10.1007/978-94-0072351-1 4

Govindaraju, R. S. (2000). Artificial neural networks in hydrology: I.:Preliminary concepts. J. Hydrol. Eng., 5(2), 115-123.

Haigh, T., Koundinya, V., Hart, C., Klink, J., Lemos, M., Mase, A. S., ... Widhalm, M. (2018). Provision of climate services for agriculture: Public and private pathways to farm decisionmaking. Bull. American Meteor. Soc., 99(9), 1781-1790. https://doi.org/10.1175/BAMS-D-17-0253.1

Irmak, A., \& Kamble, B. (2009). Evapotranspiration data assimilation with genetic algorithms and SWAP model for ondemand irrigation. Irrig. Sci., 28(1), 101-112. https://doi.org/10.1007/s00271-009-0193-9

Jensen, M. E., \& Allen, R. G. (2016). Evaporation, evapotranspiration, and irrigation water requirements. Reston, VA: ASCE. https://doi.org/10.1061/9780784414057

Kelley, J., \& Higgins, C. (2018). Computational efficiency for the surface renewal method. Atmos. Meas. Tech., 11(4), 2151-2158. https://doi.org/10.5194/amt-11-2151-2018

Kelley, J., \& Pardyjak, E. R. (2019). Using neural networks to estimate site-specific crop evapotranspiration with low-cost sensors. Agron., 9(2), 108. https://doi.org/10.3390/agronomy9020108

King, B. A., \& Shellie, K. C. (2016). Evaluation of neural network modeling to predict non-water-stressed leaf temperature in wine grape for calculation of crop water stress index. Agric. Water Mgmt., 167, 38-52. https://doi.org/10.1016/j.agwat.2015.12.009

Knox, J. W., Kay, M. G., \& Weatherhead, E. K. (2012). Water regulation, crop production, and agricultural water management: Understanding farmer perspectives on irrigation efficiency. Agric. Water Mgmt., 108, 3-8. https://doi.org/10.1016/j.agwat.2011.06.007

Kumar, M., Raghuwanshi, N. S., \& Singh, R. (2011). Artificial neural networks approach in evapotranspiration modeling: A review. Irrig. Sci., 29(1), 11-25. https://doi.org/10.1007/s00271010-0230-8 
Leuning, R. (2007). The correct form of the Webb, Pearman, and Leuning equation for eddy fluxes of trace gases in steady and non-steady state, horizontally homogeneous flows. BoundaryLayer Meteorol., 123(2), 263-267. https://doi.org/10.1007/s10546-006-9138-5

LI-COR. (2019). EddyPro software (ver. 7.0). Lincoln, NE: LICOR, Inc.

Marek, T., Piccinni, G., Schneider, A., Howell, T., Jett, M., \& Dusek, D. (2006). Weighing lysimeters for the determination of crop water requirements and crop coefficients. Appl. Eng. Agric., 22(6), 851-856. https://doi.org/10.13031/2013.22256

Massman, W. J. (2000). A simple method for estimating frequency response corrections for eddy covariance systems. Agric. Forest Meteorol., 104(3), 185-198. https://doi.org/10.1016/S01681923(00)00164-7

Meyers, J. N., Kisekka, I., Upadhyaya, S. K., \& Michelon, G. K. (2019). Development of an artificial neural network approach for predicting plant water status in almonds. Trans. ASABE, 62(1), 19-32. https://doi.org/10.13031/trans.12970

Molden, D., Oweis, T., Steduto, P., Bindraban, P., Hanjra, M. A., \& Kijne, J. (2010). Improving agricultural water productivity: Between optimism and caution. Agric. Water Mgmt., 97(4), 528535. https://doi.org/10.1016/j.agwat.2009.03.023

Moncrieff, J., Clement, R., Finnigan, J., \& Meyers, T. (2005). Averaging, detrending, and filtering of eddy covariance time series. In Handbook of micrometeorology (pp. 7-31). Dordrecht, The Netherlands: Springer Atmospheric and Oceanic Sciences. https://doi.org/10.1007/1-4020-2265-4_2

Paliwal, M., \& Kumar, U. A. (2009). Neural networks and statistical techniques: A review of applications. Expert Syst. Appl., 36(1), 2-17. https://doi.org/10.1016/j.eswa.2007.10.005

Palmer, P. L., \& Hamel, J. L. (2009). Quality assurance procedures for Reclamation's AgriMet weather station network. Proc. Western Snow Conf. (pp. 123-132). Brush Prairie, WA: Western Snow Conference. Retrieved from https://westernsnowconference.org/sites/westernsnowconferen ce.org/PDFs/2009Palmer.pdf

Penman, H. L., \& Keen, B. A. (1948). Natural evaporation from open water, bare soil, and grass. Proc. Royal Soc. London A, 193(1032), 120-145. https://doi.org/10.1098/rspa.1948.0037
Perry, C. (2007). Efficient irrigation; inefficient communication; flawed recommendations. Irrig. Drain., 56(4), 367-378. https://doi.org/10.1002/ird.323

Perry, C., Steduto, P., Allen, R. G., \& Burt, C. M. (2009). Increasing productivity in irrigated agriculture: Agronomic constraints and hydrological realities. Agric. Forest Meteorol., 96(11), 1517-1524. https://doi.org/10.1016/j.agwat.2009.05.005

Peters, R. T., Hill, S., Hoogenboom, G., \& Hamel, J. (2014). Simplified irrigation scheduling on your phone or web browser. Proc. Irrigation Association Technical Conf. Fairfax, VA: Irrigation Association. Retrieved from http://www.irrigation.org/IA/FileUploads/IA/Resources/Technic alPapers/2014/SimplifiedIrrigationSchedulingOnYourPhoneOr WebBrowser.pdf

Srivastava, N., Hinton, G., Krizhevsky, A., Sutskever, I., \& Salakhutdinov, R. (2014). Dropout: A simple way to prevent neural networks from overfitting. J. Machine Learning Res., 15(1), 1929-1958.

MathWorks. (2016). Matlab R2016b (ver. 9.1). Natick, MA: MathWorks Inc.

Vickers, D., \& Mahrt, L. (1997). Quality control and flux sampling problems for tower and aircraft data. J. Atmos. Ocean. Tech., 14(3), 512-526. https://doi.org/10.1175/15200426(1997)014<0512:qcafsp $>2.0$. co;2

Walter, I. A., Allen, R. G., Elliott, R., Itenfisu, D., Brown, P., Jensen, M. E., ... Eching, S. (2005). Task committee on standardization of reference evapotranspiration. Reston, VA: ASCE.

Walter, I. A., Allen, R. G., Elliott, R., Jensen, M. E., Itenfisu, D., Mecham, B., ... Echings, S. (2000). ASCE's standardized reference evapotranspiration equation. Proc. Watershed Management Conf. Reston, VA: ASCE. https://doi.org/10.1061/40499(2000)126

Webb, E. K., Pearman, G. I., \& Leuning, R. (1980). Correction of flux measurements for density effects due to heat and water vapour transfer. Qtly. J. Royal Meteorol. Soc., 106(447), 85-100. https://doi.org/10.1002/qj.49710644707

Wilczak, J. M., Oncley, S. P., \& Stage, S. A. (2001). Sonic anemometer tilt correction algorithms. Boundary-Layer Meteorol., 99(1), 127-150.

https://doi.org/10.1023/A:1018966204465 